\title{
Detection of abnormal left ventricular wall movement during isovolumic contraction and early relaxation Comparison of echo- and angiocardiography
}

\author{
J. H. DORAN ${ }^{1}$, T. A. TRAILL, D. J. BROWN, AND D. G. GIBSON
}

From Brompton Hospital, London

SUMMARY Abnormal left ventricular wall movement during isovolumic contraction and early relaxation was assessed from simultaneous apex and echocardiograms in 50 patients with ischaemic heart disease, and compared with estimates from the corresponding digitised left ventriculograms. During isovolumic contraction, a normal angiogram was accompanied by normal apex-dimension relations in 13 out of 14 cases. In 19 cases, there was angiographic evidence of discrete outward wall movement during isovolumic contraction which was associated with abnormal apex-dimension relations in 15. During isovolumic relaxation, of 14 cases who were normal angiographically, apex-dimension relations were normal also in 11, while in 36 patients with abnormal wall movement on angiogram, apex-dimension relations were abnormal in 30. Correlation was less good between echocardiographic and angiographic estimates of left ventricular minor dimension $(r=0.75)$, and was absent between those of peak rates of dimension change during systole and diastole. Asynchronous onset of inward wall movement and the distribution of regional abnormalities of overall wall movement amplitude were unrelated to apex-dimension relations. The apex-dimension relation is thus a sensitive and specific means of detecting abnormalities of left ventricular wall movement during isovolumic contraction and early relaxation, unaffected by other manifestations of left ventricular disease.

Analysis of the time relations between left ventricular dimension measured by echocardiography and the apex cardiogram has been suggested as a method of detecting incoordinate contraction (Venco et al., 1977). This method depends on the apex cardiogram and left ventricular pressure being virtually synchronous during the periods of isovolumic relaxation and early relaxation. In normal subjects, changes in left ventricular dimension at these times are small, but when regional abnormalities of left ventricular function are present, significant changes in left ventricular cavity shape may occur, with corresponding loss of efficiency of energy transfer from the myocardium to the circulation (Gibson and Brown, 1976). Such shape changes have been documented by angiography during isovolumic contraction (Karliner et al., 1971) and relaxation (Altieri et al.,

1Present address: Medical Center Hospital, Odessa, Texas, USA.

Received for publication 22 July 1977
1973; Hamby et al., 1974; Ruttley et al., 1974; Wilson et al., 1975; Gibson et al., 1976), and also by echocardiography during early relaxation as a dimension increase before mitral valve opening (Upton et al., 1976). It was the purpose of the present study to investigate the relation between abnormalities of left ventricular wall movement during isovolumic contraction and early relaxation determined echocardiographically and compare them with angiographic data from the same patient.

\section{Subjects and methods}

Fifty patients were studied, who required cardiac catheterisation and left ventriculography for the investigation of chest pain, thought to be angina. Forty-five had abnormal coronary arteriograms, and in the remaining 5, left ventricular disease was generalised and severe, so that coronary arteriography was not performed. In all patients, simultaneous echo and apex cardiograms were obtained 
within 7 days of the catheter study. The criteria for inclusion in the series included a primary diagnosis of coronary artery disease, and technically satisfactory echocardiograms, apex cardiograms, and left ventriculograms. Invasive and noninvasive studies were assessed independently by two separate observers who were unaware of the results of the other study.

ECHOCARDIOGRAMS AND APEX CARDIOGRAMS Echocardiograms were recorded with a Smith-Kline 20 Ultrasonoscope, and either a Cambridge Instruments or a Honeywell 1851 strip chart recorder, using a $2 \cdot 25 \mathrm{MHz}$ transducer. Clear, continuous echoes were obtained from the posterior surface of the septum and the endocardium of the posterior wall of the left ventricle at the level of the mitral valve. Simultaneous apex cardiograms were recorded from the point of maximum impulse, with the patient in the left semilateral position. A Cambridge Scientific Instruments transducer was used, with a $3 \mathrm{~cm}$ cup, a time constant of $4 \mathrm{~s}$, and a lower frequency limit of $0.04 \mathrm{~Hz}$. All recordings were made photographically at a paper speed of $100 \mathrm{~mm} / \mathrm{s}$.

\section{ANGIOCARDIOGRAMS}

Patients were premedicated 1 hour before angiography with oral amylobarbitone sodium. Left ventriculography was performed before coronary arteriography, with the patient in either the posteroanterior or the $30^{\circ}$ right anterior oblique projection. An injection of 35 to $40 \mathrm{ml}$ Triosil was made into the left ventricle at a rate of 15 to $25 \mathrm{ml} / \mathrm{s}$, and cine film exposed at 50 frames/s. Calibration was by means of a grid at mid-chest level. Ectopic and postectopic beats were not studied.

\section{ANALYSIS OF ANGIOGRAMS}

Angiographic analysis was performed using methods previously described. The overall amplitude of wall movement was assessed from superimposed cavity outlines from successive cine frames (Gibson and Brown, 1975), and was assessed as being normal, or showing anterior, inferior, or generalised hypokinesis, or aneurysm. Changes in transverse left ventricular dimension (Gibson and Brown, 1975) were studied in all patients. From continuous plots of this dimension, values at end-diastole and endsystole were read off along with peak rates of change during systole and diastole from the corresponding curve of the first derivative with respect to time. In order to show regional patterns of endocardial movement in greater detail, isometric and contour displays were prepared from each angiogram (Gibson et al., 1976). For simplicity, the cavity was considered in three regions: anterior, apical, and inferior.
Two types of systolic abnormality were defined, and considered separately: (1) prolongation to more than $100 \mathrm{~ms}$ (the upper limit of normal, unpublished observations) of the period over which inward wall movement began in different regions of the cavity, and (2) the additional presence of a region of discrete outward movement of endocardium by $2 \mathrm{~mm}$ or more from the position of the cavity outline in the cine frame in which it showed maximum area. During isovolumic relaxation, two types of abnormality were also defined (Gibson et al., 1976): (1) outward endocardial movement by more than $7 \mathrm{~mm}$ between the time of minimum cavity area and the onset of mitral valve opening, and (2) inward endocardial movement of more than $2 \mathrm{~mm}$ during this period, whether or not accompanied by outward movement elsewhere.

\section{ANALYSIS OF ECHOCARDIOGRAMS}

Left ventricular end-diastolic and end-systolic dimension and peak rates of change of dimension during systole and diastole were read off from continuous plots of left ventricular dimension and its first derivative with respect to time (Gibson and Brown, 1973). The pattern of septal movement was assessed as normal, akinetic (when the amplitude of movement was less than $1 \mathrm{~mm}$ ), or reversed. Apexdimension loops were constructed and analysed on the basis of values established in a previous study (Venco et al., 1977). Normally, 0 to 15 per cent of the total reduction in dimension occurs during the time of the inscription of the upstroke of the apex cardiogram, between its onset and the ' $E$ ' point, while during the downstroke, between the ' $k$ nee' and the ' $O$ ' point, dimension increases by 7 to 30 per cent of the total change, these figures representing the 95 per cent confidence limits around the two mean values. Values outside these limits were taken as abnormal, those above and below being considered separately. No other attempt at quantification was made.

On the basis of this information, comparisons were made of end-diastolic and end-systolic dimension, peak rate of change of dimension during systole and diastole, and the presence of abnormalities of wall movement during the isovolumic periods. The results were assessed by linear regression analysis, Fisher's exact test, or the $\chi^{2}$ test, as appropriate.

\section{Results}

\section{ECHOCARDIOGRAMS}

End-diastolic dimension ranged from 3.5 to $9.4 \mathrm{~cm}$, with a mean ( $\pm 1 \mathrm{SD}$ ) of $5 \cdot 4 \pm 0.2 \mathrm{~cm}$. Mean endsystolic dimension was $3.9 \pm 1.1 \mathrm{~cm}$, with a range 
of 2.0 to $7.6 \mathrm{~cm}$. The peak rate of change of dimension during systole was between 5 and $15 \mathrm{~cm} / \mathrm{s}$, and during diastole between 4 and $33 \mathrm{~cm} / \mathrm{s}$; these values were not normally distributed.

The apex-dimension loop was abnormal in 42 of the 50 patients. The commonest abnormality was an abnormally large increase in dimension during the downstroke of the apex cardiogram (29 cases) or an abnormal decrease during the upstroke (18 cases). Twenty patients had an abnormality of early relaxation only; in 17 this consisted of an abnormal increase in dimension before the ' $O$ ' point, and in 3 a reduction. In 6 patients, abnormalities were confined to isovolumic contraction, and in all consisted of a reduction in dimension. In 16 patients, abnormal dimension changes occurred during both upstroke and downstroke; 12 of these showed a decrease in dimension during the upstroke and an increase during the downstroke, and in 4 the reverse pattern occurred. The combination of an increase or of a decrease in dimension during both upstroke and downstroke did not occur, a distribution of abnormalities not explicable on a random basis $(P<0.001)$. Abnormalities of movement of the interventricular septum, either akinesis (5 patients) or reversal of the normal pattern of movement ( 9 patients) are shown in more detail in Table 1, but showed no statistically significant relation to the configuration of the loop.

Table 1 Relation between apex-dimension loop and septal movement

\begin{tabular}{lllll}
\hline $\begin{array}{l}\text { Septal } \\
\text { movement }\end{array}$ & \multicolumn{3}{l}{ Apex-dimension loop } & \\
\cline { 2 - 5 } & Normal & $\begin{array}{l}\text { Upstroke } \\
\text { abnormal }\end{array}$ & $\begin{array}{l}\text { Downstroke } \\
\text { abnormal }\end{array}$ & $\begin{array}{l}\text { Both } \\
\text { abnormal }\end{array}$ \\
\hline Normal & 5 & 6 & 14 & 11 \\
Akinetic & 2 & 0 & 2 & 1 \\
Reversed & 1 & 0 & 3 & 5 \\
\hline
\end{tabular}

\section{ANGIOCARDIOGRAMS}

End-diastolic dimension ranged from 4.8 to $7 \cdot 2 \mathrm{~cm}$, mean $5.7 \pm 0.7 \mathrm{~cm}$, and end-systolic dimension from 2.0 to $6.0 \mathrm{~cm}$, mean $3.7 \pm 1.2 \mathrm{~cm}$. Analysis of superimposed cavity outlines revealed that the amplitude of wall movement was normal in all regions in 11 patients, reduced anteriorly in 7 , and inferiorly in 17;10 had generalised hypokinesis and 5 had apical aneurysms. Thirty-six patients had abnormal left ventricular wall movement during isovolumic contraction, 17 showing asynchronous onset only, and 19 a region of discrete outward movement. Thirty-six showed abnormalities of isovolumic relaxation, 4 with increased outward wall movement only and 32 with inward movement between the time of minimum cavity area and mitral valve opening.

\section{COMPARISON OF METHODS}

Estimates of end-diastolic and end-systolic dimension by the two techniques were related by the regression equation:

Echo dimension $=0.6$ (angio dimension) $+2.1 \mathrm{~cm}$

$r=0.75$, standard error of the estimate $0.7 \mathrm{~cm}$, $P<0.001$. There was no significant correlation between estimates made by the two methods of peak rates of change of dimension during systole or diastole.

The results of the comparison between the two methods in detecting abnormalities of wall movement during isovolumic contraction are shown in Table 2. In 13 out of 14 cases, a normal left ventriculogram was accompanied by a normal apexdimension loop. Conversely, when the angiogram showed a discrete area of outward movement (19 cases) the apex-dimension loop was abnormal in 15. In the intermediate group, in whom the angiogram showed asynchronous onset of contraction only (17 cases), the apex-dimension loop was abnormal in only 3 .

The results of a similar comparison during isovolumic relaxation are shown in Table 3 . A normal angiogram was accompanied by a normal apexdimension loop in 11 out of 14 cases. When abnormal inward movement was present on the angiogram (32 cases), the apex-dimension loop was abnormal in 27. Increased outward movement was the only angiographic abnormality in 4 cases, and in 3 the corresponding loop was also abnormal.

An attempt was made to predict the regional

Table 2 Isovolumic contraction abnormalities

\begin{tabular}{|c|c|c|c|}
\hline \multirow[t]{2}{*}{ Angiogram } & \multicolumn{3}{|c|}{ Apex-dimension loop } \\
\hline & Normal & $\begin{array}{l}\text { Increase in } \\
\text { dimension }\end{array}$ & $\begin{array}{l}\text { Decrease in } \\
\text { dimension }\end{array}$ \\
\hline $\begin{array}{l}\text { Normal } \\
\text { Asynchronous onset } \\
\text { Discrete outward } \\
\text { movement }\end{array}$ & $\begin{array}{r}13 \\
13 \\
4\end{array}$ & $\begin{array}{r}0 \\
3 \\
14\end{array}$ & $\begin{array}{l}1 \\
1 \\
1\end{array}$ \\
\hline
\end{tabular}

Table 3 Isovolumic relaxation abnormalities

\begin{tabular}{llll}
\hline Angiogram & \multicolumn{3}{l}{ Apex-dimension loop } \\
\cline { 2 - 4 } & Normal & $\begin{array}{l}\text { Increase in } \\
\text { dimension }\end{array}$ & $\begin{array}{l}\text { Decrease in } \\
\text { dimension }\end{array}$ \\
\hline Normal & 11 & 2 & 1 \\
Outward movement & 1 & 1 & 2 \\
Inward movement & 5 & 24 & 3 \\
\hline
\end{tabular}


Table 4 Relation between apex-dimension loop and regional wall movement amplitude

\begin{tabular}{lllll}
\hline Angiogram & \multicolumn{3}{l}{ Apex-dimension loop } & \\
\cline { 2 - 5 } & Normal & $\begin{array}{l}\text { Abnormal } \\
\text { upstroke }\end{array}$ & $\begin{array}{l}\text { Abnormal } \\
\text { downstroke }\end{array}$ & $\begin{array}{l}\text { Both } \\
\text { abnormal }\end{array}$ \\
\hline $\begin{array}{l}\text { Normal } \\
\begin{array}{l}\text { Anterior } \\
\text { hypokinesis }\end{array}\end{array}$ & 1 & 2 & 4 & 3 \\
$\begin{array}{l}\text { Inferior } \\
\text { hypokinesis }\end{array}$ & 4 & 0 & 3 & 3 \\
$\begin{array}{l}\text { Generalised } \\
\text { hypokinesis }\end{array}$ & 2 & 2 & 6 & 5 \\
Aneurysm & 0 & 0 & 3 & 5 \\
\hline
\end{tabular}

distribution of abnormalities of wall movement amplitude throughout the cardiac cycle from the apex-dimension loop, but no statistically significant correlation was found (Table 4).

\section{Discussion}

Abnormalities of left ventricular wall movement are common in ischaemic heart disease, and represent an important mechanism of impairment of cardiac function in this condition. The most widely studied have been a regional or generalised reduction in the amplitude of wall movement, or aneurysm formation. These disturbances are usually detected by direct inspection of the angiogram or from superimposed end-diastolic and end-systolic cavity outlines (Herman and Gorlin, 1969). Much more difficult to recognise, however, are abnormalities of timing, in which overall amplitude and direction may be quite normal. These may occur at any time throughout the cardiac cycle, but their major effects are to be seen during the periods of isovolumic contraction or relaxation (Gibson and Brown, 1976). They may be detected by echocardiography or by angiograms suitably displayed, and in the present study these two methods have been compared.

Both of these techniques have limitations in studying regional left ventricular wall movement, though they are to some extent complementary. M-mode echocardiography allows only a small part of the cavity to be studied compared with the more comprehensive view obtained by angiography. However, it gives unequivocal information about endocardial position throughout the cardiac cycle, unlike angiography, where the outer border of the cavity may not define the endocardium at endsystole. Though the repetition frequency of the echocardiograph is $1000 / \mathrm{s}$, compared with a frame rate of 50/s for angiography, it seems likely that the frequency response of either technique is adequate for the display of these movements. A potential disadvantage of angiography is that endocardial movement may be the result of overall displacement of the heart within the thorax. This does not apply to echocardiography when a single dimension is studied, but may do so when attempts are made to quantify septal movement. It is thus significant that in spite of these limitations, there was substantial agreement between the two techniques, suggesting that either may be used to detect such abnormal wall motion. This agreement may seem surprising, but its basis appears to be that during an isovolumic period, localised wall movement is not possible, and inward movement in one place must be accompanied by net equal and opposite outward movement elsewhere. It follows, therefore, that wall movement during either of the isovolumic periods may be either the primary abnormality itself, or a compensatory effect in a region of otherwise normal function. These disturbances of isovolumic contraction or relaxation are thus seen to be generalised, involving the whole ventricle, so that their presence can be detected by observation of wall movement in any part. Correlation between echocardiography and angiography in detecting their presence, though not in quantifying the amplitude and distribution of the movements of which they are comprised, is not likely, therefore, to be affected by the two techniques studying different regions of the ventricle. These considerations do not apply to estimates of cavity dimension or peak wall velocities, where agreement between the two methods was significantly less good than that seen in patients with valvular heart disease or cardiomyopathy and a more co-ordinate contraction pattern (Gibson and Brown, 1975). Similarly, apex-dimension loops did not correlate with the overall amplitude of regional wall movement shown on the angiogram or with the pattern of septal movement. Apex-dimension loops are thus specific in detecting abnormalities of isovolumic contraction or relaxation, and agreement between the two methods cannot be explained merely on the basis of generalised left ventricular damage.

The left ventricular dimension changes during isovolumic contraction and relaxation recorded by echocardiography were not random, but appeared to follow well-defined patterns. A reduction in dimension during the upstroke of the apex cardiogram was much commoner than an increase, while during the downstroke of the apex cardiogram the reverse was the case. If abnormal movement was present during both these periods, then a reduction in dimension during isovolumic contraction was always accompanied by an increase during early relaxation, and vice versa. It seems likely that during isovolumic contraction the primary abnormality is 
an increase in dimension caused by late onset of contraction, while a reduction in dimension represents the corresponding compensatory effect. Conversely, during isovolumic relaxation, previous studies have suggested that inward wall movement is the primary abnormality, and an increase in dimension the secondary effect (Gibson et al., 1976). The observed patterns of wall movement are compatible with these ideas. A reduction in dimension during the upstroke or an increase during the downstroke were approximately four times as common as the reverse, indicating the relative frequency with which the ultrasound beam traversed the normal as distinct from the abnormal region. Similarly, when wall movement is abnormal during upstroke and downstroke, the pattern is either that of the primary abnormality or of compensatory behaviour in both. Abnormalities of relaxation are commoner than those of contraction, which may indicate that the presence of the latter is evidence of more severe left ventricular disease.

The close agreement between echocardiographic and angiographic methods in detecting isovolumic wall movement suggests that one technique may be used to interpret the results of the other. Thus, it initially seemed likely that asynchronous onset of inward wall movement on the angiogram might represent the behaviour of otherwise normal myocardium in response to outward movement elsewhere, in a region not visualised in the angiographic projection used. However, the very low incidence of echocardiographic manifestations in patients in whom this was the only angiographic abnormality at the start of systole clearly indicates that this is not the case, and that some other explanation must be sought, such as prolonged activation or overall movement of the heart within the thorax.

In spite of the close agreement between these two methods, they cannot be regarded as interchangeable. Angiography gives topographical information which is inaccessible to M-mode echocardiography, and which is clearly essential in the investigation of patients with ischaemic heart disease. However, incoordinate contraction patterns can be detected very much more simply by echocardiography than with the rather complex methods required for processing angiograms, and also noninvasively, so that repeated observations can be made. In addition, the results are presented in a form which stresses the physiological consequences of incoordinate contraction in a way which may not be apparent from the delineation of a series of anatomical abnormali- ties by angiography. The results of this study, therefore, seem to justify the more extended use of echocardiography in a clinical setting to detect incoordinate contraction as a manifestation of left ventricular disease, and to monitor the effects of therapeutic interventions designed to prevent its occurrence or minimise its effects.

The computing equipment used in this study was provided by the D.H.S.S. as part of their experimental programme.

\section{References}

Altieri, P. I., Witt, S. M., and Leighton, R. F. (1973). Left ventricular wall motion during the isovolumic relaxation period. Circulation, 48, 499-505.

Gibson, D. G., and Brown, D. (1973). Measurement of instantaneous left ventricular dimension and filling rate in man, using echocardiography. British Heart fournal, 35, 1141-1149.

Gibson, D. G., and Brown, D. J. (1975). Measurement of peak rates of left ventricular wall movement in man: comparison of echocardiography with angiography. British Heart fournal, 37, 677-683.

Gibson, D. G., and Brown, D. J. (1976). Assessment of left ventricular systolic function in man from simultaneous echocardiographic and pressure measurements. British Heart fournal, 38, 8-17.

Gibson, D. G., Prewitt, T. A., and Brown, D. J. (1976). Analysis of left ventricular wall movement during isovolumic relaxation and its relation to coronary artery disease. British Heart fournal, 38, 1010-1019.

Hamby, R. I., Aintablian, A., Tabrah, F., Rekky, K., and Wisoff, S. (1974). Late systolic bulging of the left ventricle in patients with angina pectoris. Chest, 65, 169-175.

Herman, M. V., and Gorlin, R. (1969). Implications of left ventricular synergy. American fournal of Cardiology, 23, 538-547.

Karliner, J. S., Bouchard, R. J., and Gault, J. H. (1971). Dimensional changes in the human left ventricle prior to aortic valve opening. A cineangiographic study in patients with and without left heart disease. Circulation, 44, 312-322.

Ruttley, M. S., Adams, D. F., Cohn, P. F., and Abrams, H. (1974). Shape and volume changes during isovolumetric relaxation' in normal and asynergic ventricles. Circulation, 50, 306-316.

Upton, M. T., Gibson, D. G., and Brown, D. J. (1976). Echocardiographic assessment of abnormal left ventricular relaxation in man. British Heart fournal, 38, 1001-1009.

Venco, A., Gibson, D. G., and Brown, D. J. (1977). Relation between apex cardiogram and changes in left ventricular pressure and dimension. British Heart fournal, 39, 117-125. Wilson, C. S., Kreuger, S., Forker, A. D., and Weaver, W. F. (1975). Correlation between segmental early relaxation of the left ventricular wall and coronary occlusive disease. American Heart fournal, 89, 475-479.

Requests for reprints to Dr D. G. Gibson, Cardiac Department, Brompton Hospital, Fulham Road, London SW3 6HP. 